\title{
Emerging Identities of Foreign Domestic Workers in Singapore
}

\author{
Lydia Kanelli Kyvelou \\ Kokkaliari \\ Cultural Studies, Postgraduate \\ Program(Pascasarjana) \\ Universitas Sebelas Maret, \\ Indonesia \\ yd.kan.kyv.kokk@gmail.com
}

\author{
Sri Kusumo Habsari \\ English Department \\ Faculty of Cultural Sciences \\ Universitas Sebelas Maret, \\ Indonesia \\ skhabsariestaff.uns.ac.id
}

\author{
Mugijatna \\ English Department \\ Faculty of Cultural Sciences \\ Universitas Sebelas Maret, \\ Indonesia \\ ykmugijatna@gmail.com
}

Syarif Hidayatullah State Islamic University Jakarta, Indonesia

Abstract--- In post-industrial societies, the right to work has institutionally set time off work. Leisure, thus, affects the process and the span of negotiations and contestations of migrant's identities, producing and transforming their cultural capital. This paper explores the emerging identities of foreign domestic workers from Indonesia and the Philippines in Singapore. It shows how their transmigrants' identities are constructed, transformed and negotiated in the host community. The recently acquired right of a rest day for FDW in Singapore allows to investigate a new set of integration narratives and identity formations which prevail in correlation to the use of their cultural capital viewed through their choices of leisure. At the moment, more than $80 \%$ of FDW residing in Singapore come from the two countries, both categorized among the biggest sending nations of the region. The article contextualizing their migration- specific cultural capital aims to contribute to the discussion of intra-migrant differentiations of gender, ethnicity and class, which produces modes of validation other than national capital. Research employs a case-study with embedded units, collecting data through direct observation and in-depth interviews at Lucky Plaza, meeting hub of Indonesians and Philippines in Singapore. A new identity has emerged as a consequence of their quotidian lived realities. Their trajectory from home to receiving locations and the accessibility of public spaces has enabled them to reconstruct their identities of being here and elsewhere simultaneously. Rest day weekly has enabled FDW to become themselves active subjects who potently decide on their distribution of their personal time.

Keywords--- foreign domestic worker; migration-specific cultural capital; identity; leisure; Singapore

\section{INTRODUCTION}

Our contemporary social realities are constructed by new configurations between the global and the local, space and time. A direct result of globalization, this assemblage is particularly manifested in the identities of transient migrant workers.
This paper explores identity construction within the context of three ASEAN countries, namely Indonesia, the Philippines and Singapore. Much of what constitutes culture exists in the form of tacit knowledge and can be found in "the cultural habitus of daily living" [1]. In that sense, this research aims to further the mutual understanding of the diverse cultures in the region and conceptualizes their contact in the transnational expression of migration trajectories.

This paper identifies the emerging identities of foreign domestic workers from Indonesia and the Philippines in Singapore. We illustrate trans-migrants' identities constructed, transformed and negotiated within the host community by intercultural communication in correlation to the use of their cultural capital, especially as a result to the two recent groundbreaking events: regulation of a resting day weekly and the minimum wages negotiation. The focus is on their emerging transnational (foreign) identities witnessed through their choice of leisure, and not in their home identities prior to immigration (i.e. being Indonesian or Philippines).

In a cultural studies perspective, this paper draws from self-narratives of foreign domestic workers from the two island nations residing in Singapore. It explores the ways in which intimate and foreign mobile subjectivities inform and stimulate new forms of identities. According to Bourdieu [2] the "social world is accumulated history" and the notion of capital should be reintroduced in the pursuit of meticulously systematized analytic categories. Furthermore, it is employed to emphasize the limitations in the range of possible choices conducted in the social sphere and the conditioning of agents in respect to these choices. These may be economic, social and/ or cultural. Here, we illuminate the application and development of migration-specific cultural capital exercised by transient migrant workers in Singapore. 
This paper especially focuses at the embodied cultural capital which comprises the knowledge that is consciously acquired and passively inherited, through the process of socialization within a culture and tradition. This type of cultural capital can't be transmitted, but it is impressed upon the person's social field and sets of dispositions, thus, influencing both the person's taste and specifying the person's choices.

While in traditional societies, productive and nonproductive activities were intermingled and didn't have clear institutional or practical boundaries, in modern societies paid employment has institutionally delineated time off work [3]. In post-industrial societies, in which service economies have superseded the traditional industrial sectors as the main spheres of employment, leisure gets involved in the processes of building an individual's social and cultural capital. Leisure has become a "venue for making and expressing identity" [4].

Recent times have witnessed the loosening of class distinctions [5]. Identities, then, no longer governed by production logics shifted to a paradigm of consumption practices [6] sutured into lifestyles. According to Giddens [7], these social (cultural) practices became "decisions not only about how to act but who to be". Leisure is gaining in significance as a factor of performing one's identity. Thus, the leisure choices and practices provide insights of both 'what one does' and 'who one is'. Accessibility, deprivation and participation to leisure venues and activities can reinforce discrimination and segregation of individuals and groups. In that light, leisure choices also illustrate this intersectional exclusion which is understood as "the amplification and deepening of exclusion of individuals who belong to more than one marginalized category" [8]. This case study illuminates strategies of inclusion and participation (heterotopias) of foreign domestic workers from Indonesia and the Philippines in Singapore; a group admittedly prone to varied levels of marginalization.

This paper relies on the spoken word (selfnarrative) of active agents, focusing on the lives of foreign domestic workers as told through their own stories. The 'real life question' of mobilities as a way of being in the world is looked through the paradigms prevailing by the told stories of these women, being practiced, embodied, experienced and represented in a variety of ways [9]. In this view, this paper elaborates on three central theoretical notions: (a) cultural change and cultural capital, (b) identity, and (c) women.

During migration processes, practices from the home country are re-presented (Darstellen) in the events of the present in the host community. Hence, they are set against a different set of codes and entail different social and cultural values which are made into new entities; the 'newly-emergent realities' [1]. In other words, migration reinforces cultural change whereby some past cultural practices are modified, revised, reinvented and embedded within the present conditions of the transmigrant. The transmigrant herself moves in spaces encompassing the here and there, the home and away within time frames of always 'emerging-present' when present is embedded in the past and the future, similarly, embedded in the present [1]. This identity formation coincides with the Bourdieusian [10] idea of the liminality of human agency which is socially and culturally predetermined and forms part of a person's habitus and social field.

The process of subjectivization is not expressed and doesn't unfold in a unilateral manner. In that respect, a subject simultaneously identifies and doesn't identify with parts of the narratives whom which s/he is immersed and subscribes to. The subject enhances, resists and customizes these narratives in accordance to the personal narration based on a sedimentation model of flow within space, time, and oneself. This aspect of subjectivity concords with postmodern perceptions of identity as fluid, fragmented, always already hybrid and emerging. It opposes the Cartesian idea of an 'undivided' subject where desires and interests are untied and the same. The subject, according to Hall [11], "assumes different identities at different times, identities which are not unified around a coherent 'self'. Thus, in the case of empirical identity one supposes a partial identity (temporal), that is some properties are identical, but others are not. "Identity coexists with difference in tacit manner [12]". The outlined correlation between identity and difference is a key aspect of this research.

Finally, women as a category is being constructed and deconstructed through discourse, thus gender is always regarded as processual and fluid. Gender is contemplated not as a natural fact of existence (we are born male and female) but as "a normalizing ideology which demarcates the acceptable and the deviant, a tool or technology which can be employed in unexpected ways by new configurations of power to manage and control people" [13]. Therefore, this last concept is a category situated in its spatial and historical limitations.

This paper chiefly aims to provide an intensive insight in the lived experiences of foreign domestic workers from Indonesia and the Philippines in Singapore. We contemplate their (dis)identification strategies drawing from their own life stories. The selected small number of informants enables us to attain a deeper and more comprehensive understanding of cultural change and the hybridization of identities. Our objective is to inform the macropolitics of global restructuring by focusing at the everyday experiences of these women and the micropolitics of their lives' choices and decisions [14]. 


\section{METHODS}

This is a qualitative research that employs a holistic case study with embedded units. Indonesia and the Philippines are selected in accordance to the Mills Method of Difference, Most Similar System Design [15]. These are among the biggest sending countries in Asia: four out of five foreign domestic workers in Singapore come from Indonesia and the Philippines. The case study approach allows in-depth, multi-faceted explorations of complex issues in their real-life settings.

The data is gathered through non-participatory observation, in-depth interviews, and documentation techniques. The preliminary observation is conducted on 21-22 January 2017, while the secondary observation and the in-depth interviews are conducted on 8-9 July 2017. The informal semi-structured interviews lasted between 40 to 90 minutes and consisted of questions in four topics: (a) personal information, (b) domestic work and time, (c) language, ethnicity, culture, religion, and (d) future aspirations, migration, leisure.

The small number of the selected population is intended to enable narrative analysis. Narrative analyses reveal the discontinuities between story and experience and focus on discourse: on the telling itself and the devices individuals use to make meaning in stories. In that sense, it shifts the importance of the positivistic 'scholasticism' of discourse analysis to the relative subjectivity of a person's interpretation. The shift is highly important for the broadening and enhancement of our understanding of lived conditions and processes. This paper employs theory/perspective triangulation and triangulation of sources, following the assumption that different interviewees are bound to have different viewpoints.

\section{RESULT AND DISCUSSION}

The participants in the research were approached in various locations, within and outside Lucky Plaza. Five women (two from Indonesia and three from the Philippines) participated in the in-depth interviews. Due to the controversy of the topic, some of them refused to be interviewed. Career and economic gains are the defining attributes of mobility patterns expressed in unskilled migrant domestic workers in Singapore. Most of them achieved a high level of agreement when it comes to reasons for their migration (providing better living condition to their families), as well as the future aspirations (entrepreneurship in the home country upon return).

Foreign domestic workers describe the life in Singapore as convenient, efficient, effective, law abiding. Their common fear regards bad employers, scamming agencies, and cheating husbands. The comparisons they make indicate that the settling society has influenced their perception of their home country. Indeed, hybridity is an inherent characteristic of any identity, yet the hybridity experienced in this case is necessarily of different quality, as it is negotiated within the transnational settings and the spaces they occupy. It is evident in the way they describe Singapore, and the way some of them use English alphabet when spelling is required.

Orchard Road in Singapore attracts many visitors, citizens, residents, tourists, temporary workers, and is especially vivid, colourful and crowded during Sundays. The informants in this study have chosen to spend their Sunday at Lucky Plaza, located in the midst of Orchard $\mathrm{Rd}$. We highlight the negotiation and hybridization of their migration-specific cultural capital as it is manifested in their choice of leisure, namely to spend their Sundays at Lucky Plaza. Foreign domestic workers from the two countries utilize Lucky Plaza as a primary meeting establishing migrant networks. These interconnected groups constitute ethnic or national enclaves but they can also be formed on basis of religious affiliations, duration of migration, proximity of working locations, and other similarities. Certainly, the groups are consisted predominantly by women who are employed in the domestic work sector and who reside in Singapore temporarily.

Sundays at Lucky Plaza enhance domestic workers transnational experience. They are creating spaces and communication in both constructions of local; at once immersed in the life of Orchard Road, Singapore on a Sunday, and simultaneously socializing among themselves in smaller groups of belonging. These activities influence their sense of belonging transnationally and inform their daily working life with opportunities of leisure. Undoubtedly, in a postindustrial society as Singapore consumerism is validated and valued through daily social and cultural practices. Nevertheless, the values of late capitalism and consumerism wouldn't necessarily be avoided in the natal homes of the domestic workers.

Lucky Plaza doesn't offer merely opportunities of shopping, but also accommodates their need to further and strengthen the ties with their homes. Indeed, as foreign domestic workers in Singapore have been deprived of the freedom of assembly and association in civil terms (they cannot form their own assemblies nor unionize), Lucky Plaza gives them the opportunity to exercise this freedom away from the political arena, between themselves as representatives in smaller groups. Foreign domestic workers in Singapore have yet to gain the right to maintain a separate residence, thus, negating their sense of privacy as an important aspect of performing self-subjunctivisation, and therefore free expression. For the above activities and in spite of its commercial purpose, Lucky Plaza has become, pragmatically speaking, an alternative venue where foreign domestic workers from Indonesia and the Philippines are able to be agents for themselves. 
Globalization processes operate on such a scale "which cut across national boundaries, integrating and connecting communities and organization in new spacetime combinations" [11]. An important result of the globalization is the constant flows of capital, goods, services, population. The former type of population flows, commonly referred to as mobility entails a range of social phenomena. In this framework, conventional understandings of belonging and identity come into question. Accordingly, foreign domestic worker's temporal mobility is characterized with more or less fixed time-frames and is typically rotational. They express their intention for repatriation, thus producing an experiential rift between the locations of residence and the locations of belonging. The cultural values, norms and practices exercised during the temporary migration trajectory in Singapore are embedded in 'newly' emergent realities formulated in the juncture of 'home' and 'residential' cultures. As Hall claims culture is a discourse "a way of constructing meanings which influences and organizes both our actions and our conceptions of ourselves" [11]. The transnational practices practiced by the domestic workers who participated in this research are taking place in spaces of contestation and resistance where agents congregate and belong to, i.e. Lucky Plaza, Orchard Rd, Singapore. The cultural capital of foreign domestic workers from Indonesia and the Philippines is a heuristic framework. This context encompasses the transient, temporary mobilities and the migration trajectories of women from the Global South (Indonesia and the Philippines) providing services for families (and women) of the Global North (Singapore). The transformation of their migration-specific cultural capital is approached by the 'leisure' perspective, thus, viewing the research subjects while their trying to satisfy their needs through their actions. The women meeting at Lucky Plaza are more than their occupation.

Bourdieu, contributing to the canon of educational sociology attempted to explain social reproduction and social inequity through 'differing cultures and modes of socialization' [16]. A general application of the concept of capital, economic, social, cultural, symbolic, etc, attest to the workings and power dynamics of the dominant classes. To Nowicka [17], Bourdieu points "to the dynamic transformations of social actor's values, orientations, beliefs and behaviors in relation to the field to which he or she becomes and is a part of'. Following the bourdieusien conceptualization of class differentials, most of the research implementing cultural capital does so to draw our attention in educational attainment and/ or achievement and the role of inter-generational transmission of habitus.

This research draws from the category of the cultural capital introduced by Bourdieu [2] and builds on in order to explain its manifestation into the specific dispositions set forward by the subjects under research in an innately different place (Singapore) space (Lucky Plaza) and time (21 $1^{\text {st }}$ century). As commonly recognized, Bourdieu wasn't concerned in the overall production of habitus or the transformation of (cultural) capital [17] and has been criticized for giving universal value to particular and historical qualities, a fallacy referred to as 'methodological nationalism' (e.g. Bourdieu explored the French academic culture and its ability to provide and protrude credentials).

A foreign domestic worker's dispositions guide the behavioural intentions that she adopts in regard to particular decisions or courses of action. The new experiences gained in the host society interact with the given 'habitus' and as a result inform their migrationspecific cultural capital. In a fashion similar to this research Erel's [18] opposes the implementation of what she coins as 'rucksack approaches' whereby individual migrants arrive with cultural resources that either fit or do not fit their new habitus. The foreign domestic workers in Lucky Plaza are active subjects whose agency is exercised in search of contentment individually and in groups. There can be no possibility for the linear reproduction of their cultural capital since in their migration trajectories the conditions of production of 'habitus' are heterologous to the conditions of the subjects functioning in it.

There are significant affinities between this casestudy of foreign domestic workers in Singapore and the one conducted by Erel for Turkish migrants in U.K. and Germany: the formulation of research both in (a) methodological, i.e. life stories, and (b) conceptual formulation, i.e. migration-specific cultural capital. On the other hand, this study emphasizes in the embodied form of migration-specific cultural capital as illustrated in the choices of leisure of transient unskilled migrant domestic workers. The temporality of the migration in question in opposition to Erel's research on resettlement, the embodied form of cultural capital in comparison to the convertibility of institutionalized capital point to similarly significant differences between the two populations under study. Yet, the chief deviation of the two studies is the occupation in which the informants are employed; here, unskilled domestic work and skilled employment in Erel's research.

Despite the differences in the formulations of the problems, concerning to migration-specific cultural capital this study has a high degree of agreement with the findings set forward by Erel's findings. Cultural Capital becomes migration-specific cultural capital through a process called "contextualized emergence"; as some of the past configurations of values and practices are preserved and others are molded or replaced by newer ones. Foreign domestic workers have a common impression about Singapore's character as an efficient and productive location. This kind of effectiveness contradicts the lived experience 
from many of the migrant-run shops located in Lucky Plaza Shills stand outside calling prospective clients in the shop, the cashier opens a conversation with a customer in their native tongue while the queue elongates as more time passes. Thus, this type of practices does not advance from dispositions which coincide with productivity. They, rather, seem to arise from cultural elements corresponding to the 'homeland's' social field which formulates their cultural capital. Simultaneously productivity is indicative of the values shared by the Singaporean post-industrial individualistic service economy of late capitalism. Whence the research subjects compare the two locations, their respective countries, to the host in favor of the latter, they illustrate a process of hybridization of their cultural capital. In other words, efficiency becomes a value which guides their assessment of their past, current and future experiences and way of living.

This transformation happens within cultural spaces. According to Claire et.al. [1], in the context of emerging-present (co-present), "new levels of consciousness are raised and this leads to the creation of new perspectives and new forms of knowledge". In this view, the new information that is integrated into the new emerging-present will also be "socially enforced by maintenance rituals and centered through meaningful social interactions involving symbolic maintenance" [1].

However not all cultural resources form an individual's cultural capital. 'Habitus' is a space of contestation and negotiation of the difference of individuality and the inertia of commonality of social reproduction. Foreign domestic workers in Singapore bring with themselves norms and values from their country of origin, namely Indonesia and the Philippines, yet their dispositions are not limited to these past cultural resources and practices. Meaningmaking in Singapore necessarily invokes the creation in situ of new forms of cultural capital, which as Erel contends 'create quite distinct dispositions'. Moreover, the women who participated in this research produce their own migrant networks and, thus, in the process of socialization they seek validation and social prestige substantiated in this new cultural capital [8]. The migrant domestic workers, then, move through public common urban spaces creating ethnic enclaves and intra-migrant networks, where they express and construct their new identities.

Due to the intimate, hard and public qualities of their employment requirements, foreign domestic workers from Indonesia and the Philippines in Singapore have the opportunity to express themselves and exercise their need for privacy in the public spaces where they spend their free time, enjoying leisure activities. Leisure reinforces their own "mechanisms of adaptation and identity building", bring forth leisure constraints resulted in migration, and build up "a sense of belonging to a new place" [8]. Thus, leisure activities in Lucky Plaza are performed within a particular social arena ('field'). It facilitates the construction and transformations of their identities and informs an individual's social and cultural capital in three ways. These processes occur in leisure activities resulting to building one's image, maintaining social networks and developing emotional intelligence [3].

\section{CONCLUSION}

This research shows that a new identity of the foreign domestic workers from Indonesia and the Philippines in Singapore has emerged as a consequence of their recent acquisitions: a rest day right and negotiation of minimal wages and working conditions. Their trajectory from home to receiving locations and the accessibility of public spaces has simultaneously forced and enabled them to (re)construct their identities of being here and elsewhere simultaneously. This process unquestionably influenced the (re)construction of their identities through (dis)identification, by belonging and not in a reciprocal movement. This illuminates the hybridity of their identities as they move back and forth within the dynamics of center/periphery in postcolonial and globalized societies.

Migration studies have been restricted to managerial language and policy remarks approaching the subjects of the research as units to be governed [19]. Mobility is viewed within "a political framework of regulation, management and immigration control" [19]. This paper intends to illuminate aspects of the living conditions and choices of foreign domestic workers from Indonesia and the Philippines that evade the aforementioned methodological limitations. This sentient decision advances from the premise in situ conceptualization and frameworks display cautiously the transformation of the transmigrants' dispositions within a complex system of power relations. We contend that the uncontested valor set on modern western qualities of skilled effectiveness should no longer be the main route to understanding mobile, hybrid subjectivities.

\section{REFERENCES}

[1] R. Clair, A. Williams and A. T. Williams, "The Framework of Cultural Space," Journal of Intercultural Communication Studies, vol. XVII, pp. 1-14, 2008.

[2] P. Bourdieu, "The Forms of Capital," in Handbook of Theory and Research for the Sociology of Education, J. Richardson, Ed., New York, Greenwood, 1986, pp. 241-258.

[3] C. Rojek, The Labour of Leisure: The Culture of Free Time, London: Sage, 2010.

[4] D. Williams, "Leisure Identities, Globalization, and the Politics of Place," Journal of Leisure Research, vol. 34, no. 4, pp. 351-367, 2002. 
[5] D. Bell and J. Hollows, Eds."Historicizing Lifestyle: Mediating Taste, Consumption and Identity from the 1900s to 1970s,

"Contemporary British History, vol. 22, no. 4, pp. 599-612, 2006.

[6] R. Shields, "Spaces for the Subject of Consumption," in Lifestyle Shopping: The Subject of Consumption, R. Shields, Ed., London, Routledge, 1992.

[7] A. Giddens, Modernity and Self-Identity: Self and Society in the Late Modern Age, Stanford, California: Stanford University Press, 1991

[8] A. Horolets, "Migrants Leisure and Integration," Institute of Public Affairs, Warsaw, 2012.

[9] C. Mcllwaine, "Migrant Machismos: Exploring Gender Ideologies and Practices Among Latin America Migrants in London from a Multi-Scalar Perspective," Gender, Place \& Culture, vol. 17, no. 3, pp. 281-300, 2010.

[10] L. Sim, A Study of Planned Shopping Centres in Singapore, Singapore: Singapore University Press for the Centre for Advanced Studies, 1984.

[11] S. Hall, "The Question of Cultural Identity," in Modernity and Its Futures, Cambridge, The Open University Press, 1992, pp. 273-325.

[12] P. Kun, "European Identity between Ethnic and Civic Identities," Journal of Identity and Migration Studies (JIMS), vol. 9, no. 2, pp. 2-18, 2015. [Online]. Available: http://www.e-migration.ro/jims/Vol9_no2_ 2015/JIMS Vol9_No2_2015.pdf (retrieved May 2017).

[13] K. Phillip, "Gendered Technologies: The Politics of Feminist Migration Research," Australian Journal of Gender and Law, vol. 1, pp. 1-17, 2013.

[14] C. Mohanty, Feminism Without Borders: Decolonizing Theory, Practicing Solidarity, Durham, NC: Duke University Press, 2006.

[15] J. Savolainen, "The Rationality of Drawing Big Conclusions Based on Small Samples: in Defense of Mill's Method," Social Forces, vol. 72, no. 4, pp. 1217-1224, 1994.

[16] J. Goldthrope, "Cultural Capital: Some Critical Observations," Sociologica (Italian Journal of Sociology), vol. 2, pp. 1-23, 2007.

[17] M. Nowicka, "Bourdieu's Theory of Practice in the Study of Cultural Encounters and Transnational Transfers in Migration (Working Paper Series)," Max Planck Inst. for the Study of Religious and Ethnic Diversity, Gottingen, 2015.

[18] U. Erel, "Migrating Cultural Capital: Bourdieu in Migration Studies," Journal of Sociology, vol. 44, no. 4, pp. 642-660, 2010.

[19] R. Gutierrez, Migration, Domestic Work ans Affect: A Decolonial Approach on Value and the Feminization of Labor, New York: Routledge, 2010. 